\title{
Polymer photonic crystal dye lasers as optofluidic cell sensors
}

Christiansen, Mads Brøkner; Lopacinska, Joanna M.; Jakobsen, Mogens Havsteen; Mortensen, Asger; Blagoi, Gabriela; Dufva, Martin; Kristensen, Anders

\section{Published in:}

Conference on Lasers and Electro-Optics, 2009 and 2009 Conference on Quantum electronics and Laser Science Conference. CLEO/QELS 2009

Publication date:

2009

Document Version

Publisher's PDF, also known as Version of record

Link back to DTU Orbit

Citation (APA):

Christiansen, M. B., Lopacinska, J. M., Jakobsen, M. H., Mortensen, A., Blagoi, G., Dufva, M., \& Kristensen, A. (2009). Polymer photonic crystal dye lasers as optofluidic cell sensors. In Conference on Lasers and ElectroOptics, 2009 and 2009 Conference on Quantum electronics and Laser Science Conference. CLEO/QELS 2009 (pp. 1-2). IEEE.

\section{General rights}

Copyright and moral rights for the publications made accessible in the public portal are retained by the authors and/or other copyright owners and it is a condition of accessing publications that users recognise and abide by the legal requirements associated with these rights.

- Users may download and print one copy of any publication from the public portal for the purpose of private study or research.

- You may not further distribute the material or use it for any profit-making activity or commercial gain

- You may freely distribute the URL identifying the publication in the public portal 


\title{
Polymer Photonic Crystal Dye Lasers as Optofluidic Cell Sensors
}

\author{
Mads B. Christiansen ${ }^{1}$, Joanna M. Lopacinska ${ }^{1}$, Mogens H. Jakobsen ${ }^{1}$, \\ N. Asger Mortensen ${ }^{2}$, Gabriela Blagoi ${ }^{1}$, Martin Dufva ${ }^{1}$, and Anders Kristensen ${ }^{1}$ \\ ${ }^{I}$ DTU Nanotech, Department of Micro- and Nanotechnology \\ ${ }^{2}$ DTU Fotonik, Department of Photonics Engineering \\ Technical University of Denmark \\ DK-2800 Kongens Lyngby, Denmark \\ mads.christiansen@nanotech.dtu.dk
}

\begin{abstract}
Hybrid polymer photonic crystal band-edge lasers are chemically activated to covalently bind bio-molecules or for HeLa cell attachment using an anthraquinone (AQ) UV activated photolinker. The lasers change emission wavelength linearly with inhomogeneous cell coverage. (C)2009 Optical Society of America

OCIS codes: (140.2050) Dye Lasers; (050.5298) Photonic crystals; (280.1415) Biological sensing and sensors

Additional key words: nanoimprint, combined nanoimprint and UV lithography, Ormocer, label free sensing
\end{abstract}

We present a chemical activation method for optically pumped hybrid polymer rectangular lattice band edge lasers[1,2]. The lasers are defined in a thin film of photo-definable Ormocore hybrid polymer[3], doped with the laser dye Pyrromethene 597. They are $375 \mathrm{~nm}$ thick slab waveguides with a rectangular lattice of $100 \mathrm{~nm}$ deep air holes imprinted into the surface (Fig. 1). A frequency doubled Nd:YAG laser (532 nm, $5 \mathrm{~ns}$ pulses) is used to pump the lasers from above the chip, causing them to emit in the chip plane. A typical spectrum is shown in Fig. 2.

The lasers are fabricated in parallel on a $10 \mathrm{~cm}$ diameter wafer by combined nanoimprint and photolithography (CNP) [4]. CNP relies on a UV transparent quartz nanoimprint stamp with an integrated metal shadow mask. In the CNP process the photonic crystal is formed by mechanical deformation (imprinting) while the larger features are defined by UV exposure through the combined mask/mold.

Activation of the lasers is done photochemically using anthraquinone (AQ) photolinkers [5]. Fig. 3(a) and (b) show fluorescence intensities from lasers treated with $\mathrm{AQ}$ photolinkers with an electrophilic group (AQ-E), different concentrations of Biotin- $\mathrm{NH}_{2}$ (highest concentration on top of the figure), and finally Cy5-Streptavidin. Fig. 3(c) and (d) are closer looks at a device spotted with $62 \mu \mathrm{g} / \mathrm{ml}$ of biotin- $\mathrm{NH}_{2}$. Under green excitation (c) the laser dye is seen, and under red excitation (d) the streptavidin is seen. Note that it binds more to the polymer than the surrounding glass. Fig. 3(e) and (f) are similar images from an untreated device, showing no Cy5 signal.

Fig. 4 shows HeLa cells attached to lasers with AQ photolinker with an amino group (AQ- $\left.\mathrm{NH}_{2}\right)$ [5]. Different cell concentrations are used. Device (a) and (d) are incubated with cells under the same conditions, but (d) without AQ$\mathrm{NH}_{2}$. It is evident that cells bind specifically to AQ- $\mathrm{NH}_{2}$ treated surfaces. Fig. 5 shows laser tuning as a function of cell surface coverage when submerged in Phosphate Buffered Saline (PBS) (reference spectra taken in pure PBS). Prior to cell growth the lasers are washed in Ethanol, causing a $0.75 \mathrm{~nm}$ blueshift. The sensitivity corresponds to $5 \times 10^{-3} \mathrm{~nm}$ per cell on the laser, making it possible to detect single cells, if the laser is scaled down to a $100 \mu \mathrm{m}$ square, which should be feasible.

Our results demonstrate that nanostructured hybrid polymer lasers can be selectively chemically activated with UV sensitive photolinkers for further bioanalytical applications. This opens the possibility to functionalize arrays of optofluidic laser sensors with different bio-recognition molecules for multiplexed sensing. The linear relationship between cell coverage and wavelength indicates that the slight refractive index perturbation from the partial coverage of the sensor influences the entire optical mode, rather than breaking down the photonic crystal feedback.

[1] Mads Brøkner Christiansen, Anders Kristensen, Sanshui Xiao, and Niels Asger Mortensen, "Photonic integration in k-space: Enhancing the performance of photonic crystal dye lasers", Appl. Phys. Lett. 93(23), in press (2008).

[2] Felipe Bernal Arango, Mads Brøkner Christiansen, Morten Gersborg-Hansen, and Anders Kristensen, "Optofluidic tuning of photonic crystal band edge lasers", Appl. Phys. Lett. 91, 223503 (2007).

[3] Ormocore is commercially available from micro resist technology GmbH, Berlin, Germany, www.microresist.de.

[4] Mads Brøkner Christiansen, Mikkel Schøler, and Anders Kristensen, "Integration of active and passive polymer optics", Optics Express 15(7), 3931-3939 (2007).

[5] Gabriela Blagoi, Stephan Keller, Fredrik Persson, Anja Boisen and Mogens Havsteen Jakobsen, Photochemical Modification and Patterning of SU-8 Using Anthraquinone Photolinkers, Langmuir, 24(18), pp 9929-9932 (2008). 


\section{CTuCC2.pdf}

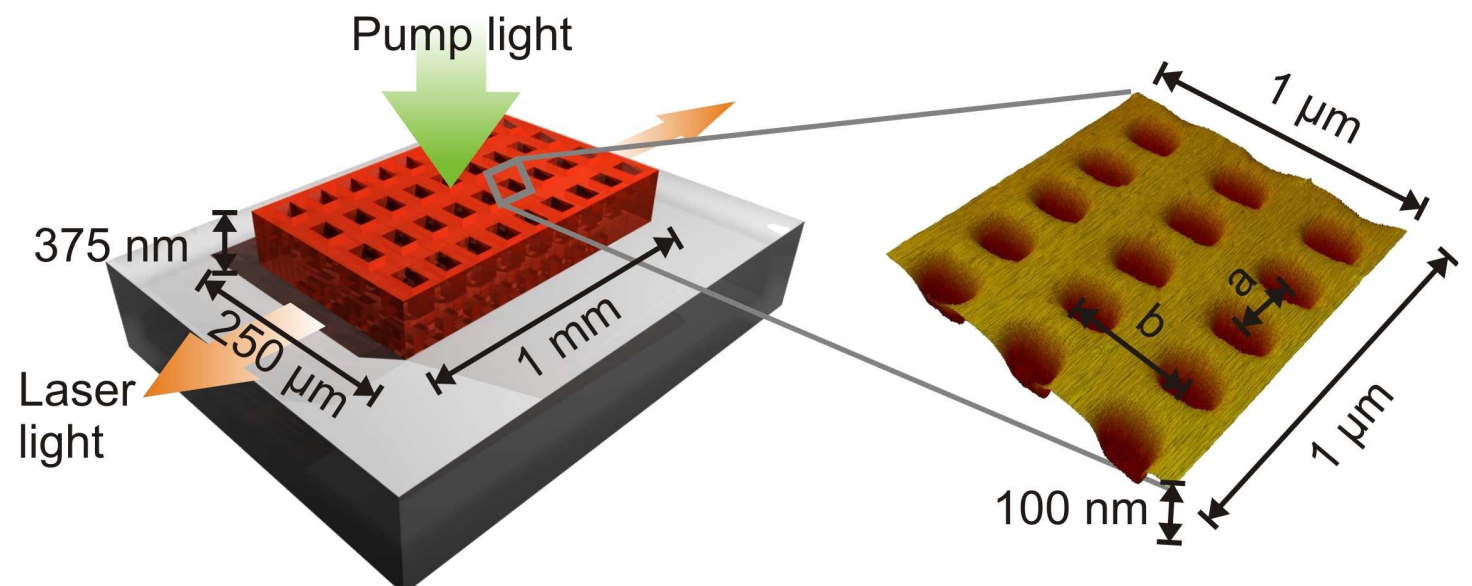

Fig. 1 Conceptual drawing of a photonic crystal band-edge laser. The lasers are Pyrromethene 597 dye doped Ormocore slab waveguides on a glass substrate. They emit in plane when pumped from above. The inset is an AFM image of the photonic crystal surface with the $a$ and $b$ lattice constants indicated.

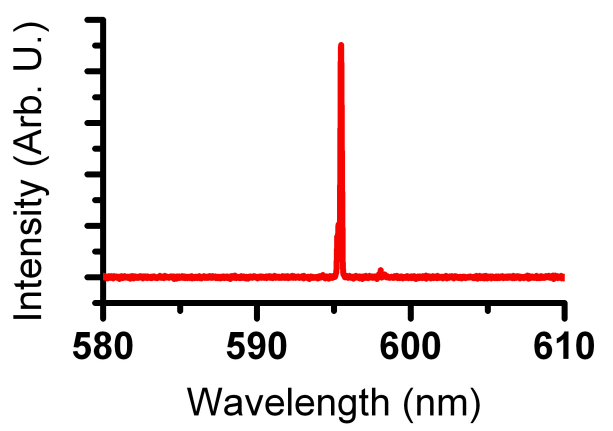

Fig. 2 A typical spectrum from a laser pumped at 4 $\mu \mathrm{J} / \mathrm{mm}^{2}$. The emission color depends on the $a$ lattice constant. It is tunable from yellow/green to red.
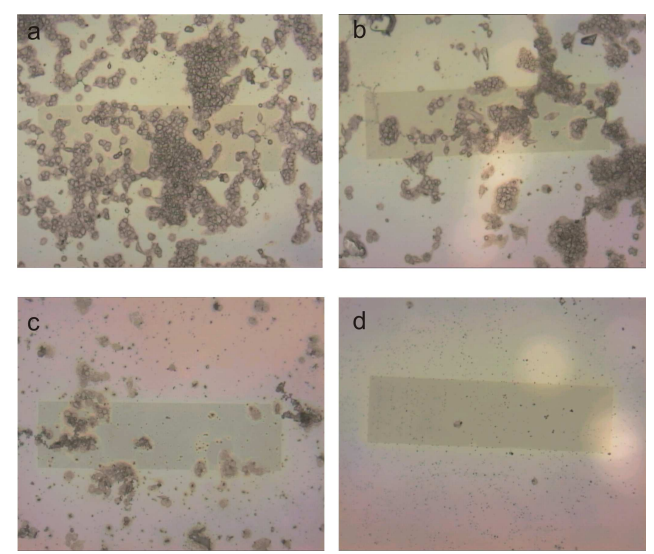

Fig. 4 Different amounts of HeLa cells grown on lasers treated with $\mathrm{AQ}-\mathrm{NH}_{2}$. The laser in (d) had the same treatment as the laser in (a), but no AQ-Link.

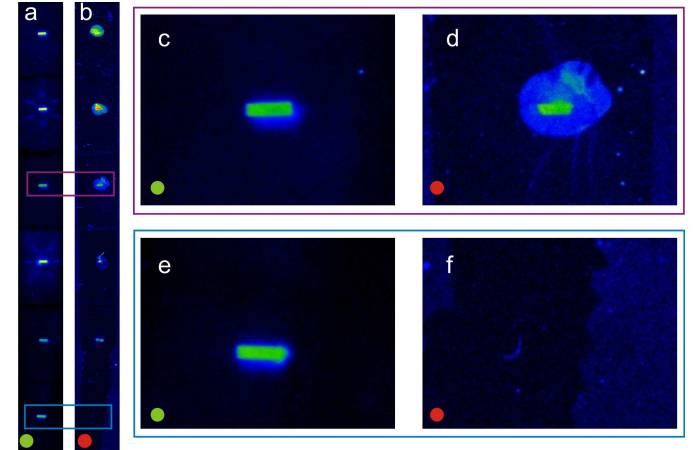

Fig. 3 Fluorescence images of laser treated with AQ-E, Biotin- $\mathrm{NH}_{2}$ and Cy5-Streptavidin. The small dots in the lower left corners indicate excitation color. See main text for explanation

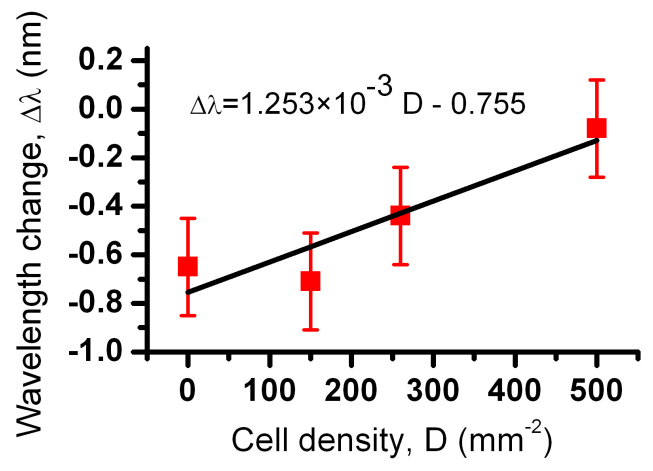

Fig. 5 Measured ( $\square$ ) wavelength change vs. cell density. A linear fit is also seen (-). The sensitivity is $1.253 \times 10^{-3} \mathrm{~nm} \mathrm{~mm}^{2}$. 